\title{
Vigny, émotions et passions, dir. S. LEDDA et S. VANDEN ABEELE-MARCHAL
}

\section{Lise Sabourin}

\section{(2) OpenEdition Journals}

Édition électronique

URL : https://journals.openedition.org/studifrancesi/31898

DOI : 10.4000/studifrancesi.31898

ISSN : 2421-5856

\section{Éditeur}

Rosenberg \& Sellier

\section{Édition imprimée}

Date de publication : 1 août 2020

Pagination : 418-419

ISSN : 0039-2944

\section{Référence électronique}

Lise Sabourin, «Vigny, émotions et passions, dir. S. LedDA et S. VANDEn ABEele-MARChal 》, Studi Francesi [En ligne], 191 (LXIV | II) | 2020, mis en ligne le 01 septembre 2020, consulté le 17 septembre 2021. URL: http://journals.openedition.org/studifrancesi/31898; DOI : https://doi.org/10.4000/studifrancesi. 31898

Ce document a été généré automatiquement le 17 septembre 2021.

\section{(†) $९$}

Studi Francesi è distribuita con Licenza Creative Commons Attribuzione - Non commerciale - Non opere derivate 4.0 Internazionale. 


\title{
Vigny, émotions et passions, dir. S. LEDDA et S. VANDEN ABEELE-MARCHAL
}

\author{
Lise Sabourin
}

\section{RÉFÉRENCE}

Vigny, émotions et passions, dir. S. LEDDA et S. VANDEN ABEELE-MARCHAL, "Bulletin de

l'Association des Amis d'Alfred de Vigny", nouvelle série, 2, 2019, 159 pp.

1 Après le numéro 1 consacré à Vigny et l'ironie romantique, cette nouvelle série du "Bulletin des Amis d'Alfred de Vigny" adopte un autre sujet lié aux affects, en traitant de Vigny, émotions et passions, thème fort à la mode en notre époque souvent prête à s'adonner à la sensiblerie passionnelle par-delà la pratique d'une vraie sensibilité. On sent aussi dans ce choix l'influence de l'Histoire des émotions d'Alain Corbin (Seuil, 2017) qui a fait magistralement le point sur ce thème propice à la créativité esthétique et littéraire. A priori, le sujet n'est pas évident pour Vigny qui, parmi les grands romantiques, est assurément celui qui a le plus voulu dompter ses passions et soumettre ses émotions à la puissance de la rationalité par la pratique de l'impassibilité opposée à la désespérance.

2 Pourtant, le romantisme étant un des mouvements particulièrement épris de lyrisme, donc de l'expression des émois de l'individu, la problématique s'avère judicieuse: comment Vigny, ce grand refoulé à la forte sensibilité native comme il l'a lui-même reconnu, s'inscrit-il dans ce courant alors qu'il cherche sans cesse à mettre à distance ses émotions personnelles, préférant par exemple la réflexion et le récit à la confidence? Le numéro tente des coups de sonde dans divers domaines de son œuvre, avec des résultats assez hétérogènes.

3 L'histoire et la politique sont abordées par deux articles. Sophie VANDEN ABEELE-MARCHAL scrute les Variations sensibles sur les émotions politiques selon Vigny (pp. 17-44): dans ce milieu éminemment lié aux «jeux de la haine et du hasard» (Les Oracles), Vigny décèle la nécessité des passions et des émotions comme moteurs de l'action, par exemple en 
traitant de la chute de la féodalité à travers «l'histoire bien simple d'un amour passionné» dans Cinq-Mars. Lui qui a lu et annoté Platon, Machiavel, Retz et Montesquieu avec ardeur, il sait combien la crainte est liée au pouvoir et retrace, par exemple dans Stello, comment le démon égalitaire et l'aristocratisme élitiste expliquent les soubresauts des régimes dont son époque ne cesse de vivre les aléas. Pierre DUPUY se penche sur Passions et dépassionnement en étudiant Séidisme et honneur dans "Servitude et grandeur militaires" (pp. 87-101): liant à sa carrière militaire l'étude du fanatisme qui a entouré le culte napoléonien, il montre comment Vigny a tenté d'en guérir ses lecteurs par l'abandon de la gloire épique au profit d'un héroïsme anonyme de l'honneur moderne.

4 Trois communications vont du côté de la poésie. Janette MCLEMAN-CARNIE cherche du côté du poète visuel, poète émotif (pp. 59-72) qu'est aussi Vigny dans ses descriptions: son élixir s'avère également olfactif et auditif pour déployer par la rhétorique sa dramatique poétique. Esther PINON discerne très bien ce qu'est l'émotion sacrée chez Vigny: passions, passion et compassion (pp. 45-57) sont les trois phases de sa créativité. La Passion christique glace à tel point les émotions qu'elle incite au mutisme en réponse au silence de Dieu; mais les passions humaines sont finalement réhabilitées par le partage compassionnel de notre condition fraternelle, libérant l'écriture poétique comme nouvelle dimension du sacré. Aurélie fOGLIA-LOISELEUR prouve excellemment combien Vigny est un cœur brûlé par la poésie (pp. 73-85). Pris dans la contradiction permanente d'afficher la seule composante intellectuelle de son être et de dompter sa sensibilité exacerbée, endiguée par son éducation et son expérience de l'armée, Vigny préfère la "plume de fer» au sanglot affectif fréquent en sa génération et fait un usage subtil du pathétique. Il pratique la froideur, l'effacement et même l'impersonnalité, mais en fait sa morale en appelle toujours à l'émotion du lecteur, sollicité par les pleurs d'Éloa sur Satan, du Christ sur Lazare ou la déploration du chasseur sur le loup mourant, renvoyant par son regard à la fraternité profonde des êtres vivants emportés par une commune condamnation.

5 Fériel younsi tente de discerner les émotions féminines ou l'intimité dévoilée en comparant quelques poésies de Vigny à des romans balzaciens (pp. 1103-114). Sylvain LEDDA note que les émotions dans "Chatterton" (pp. 115-122), qui ont tant impressionné Musset à sa création, tiennent à la triangulation en huis clos de sentiments intrinsèquement liés à l'univers théâtral: colère, peur, tristesse et pitié. Patrick BERTHIER remarque enfin que Vigny a suscité une «critique-passion» chez Guillemin (pp. 123-146), liée à sa rétraction, à l'inverse de Mauriac, envers l'homme intime, qui l'a amené à mettre exagérément en relief certains manuscrits qu'il jugeait compromettants de l'auteur.

6 Comme d'habitude, ce numéro, qui rend hommage à Simone Pirard, vice-présidente décédée, et rappelle la vie de l'association en 2016, se clôt sur la revue des autographes par Thierry BoDin qui déplore, comme tous les vignystes, que le fonds Sangnier ait été dispersé, sous la seule attention de quelques apparentés, de l'Institut et des propriétaires du Maine-Giraud, lors de la vente effectuée chez Artcurial en novembre 2016. Heureusement la Correspondance pourra continuer à publier toutes les lettres inédites qu'il comportait, dûment collectées, mais il est dommage de voir échapper à la Bibliothèque nationale des manuscrits et notes d'œuvres majeures et être séparés les trois dossiers des Mémoires révélés par Jean Sangnier. 